\title{
(2) OPEN ACCESS \\ Real-world management of treatment-naïve diabetic macular oedema: 2-year visual outcome focusing on the starting year of intervention from STREAT- DMO study
}

\author{
Masahiko Shimura (1) , Shigehiko Kitano, ${ }^{2}$ Daisuke Muramatsu, ${ }^{3}$ Harumi Fukushima, ${ }^{2}$ \\ Yoshihiro Takamura, ${ }^{4}$ Makiko Matsumoto, ${ }^{5}$ Masahide Kokado, ${ }^{6}$ Jiro Kogo, ${ }^{7}$ \\ Mariko Sasaki, ${ }^{8,9}$ Yuki Morizane, ${ }^{10}$ Takuya Utsumi, ${ }^{1}$ Takashi Koto, ${ }^{11}$ Shozo Sonoda, ${ }_{1}{ }^{2}$ \\ Takao Hirano, ${ }^{13}$ Hiroto Ishikawa, ${ }^{14}$ Yoshinori Mitamura @ (1) ${ }^{15}$ Fumiki Okamoto, ${ }^{16}$ \\ Takamasa Kinoshita, ${ }^{17}$ Kazuhiro Kimura (10 , ${ }^{18}$ Masahiko Sugimoto, ${ }^{19}$ \\ Kenji Yamashiro (0), ${ }^{20}$ Yukihiko Suzuki, ${ }^{21}$ Taiichi Hikichi, ${ }^{22}$ Noriaki Washio, ${ }^{23}$ \\ Tomohito Sato, ${ }^{24}$ Kishiko Ohkoshi, ${ }^{25}$ Hiroki Tsujinaka, ${ }_{1}^{26}$ Sentaro Kusuhara, ${ }_{1}^{27}$ \\ Mineo Kondo, ${ }^{19}$ Hitoshi Takagi, ${ }^{7}$ Toshinori Murata, ${ }^{13}$ Taiji Sakamoto $\left(\mathbb{0},{ }^{12}\right.$ on behalf of \\ Japan Clinical Retina Study (J-CREST) group
}

For numbered affiliations see end of article.

\section{Correspondence to}

Professor Masahiko Shimura, Department of Ophthalmology, Tokyo Medical University Hachioji Medical Center, Hachioji 1930998, Japan; masahiko@v101.vaio.ne.jp

Received 16 December 2019 Revised 17 February 2020 Accepted 20 February 2020 Published Online First 13 March 2020

\section{Check for updates}

(C) Author(s) (or their employer(s)) 2020. Re-use permitted under CC BY-NC. No commercial re-use. See rights and permissions. Published by BMJ.

To cite: Shimura M, Kitano S, Muramatsu D, et al. Br J Ophthalmol

2020;104:1755-1761.

\section{ABSTRACT}

Background/aims To investigate the yearly change of real-world outcomes for best corrected visual acuity (BCVA) after 2-year clinical intervention for treatmentnaïve diabetic macular oedema (DMO).

Methods Retrospective analysis of aggregated, longitudinal medical records obtained from 27 retina specialised institutions in Japan from Survey of Treatment for DMO database. A total of 2049 treatment-naïve centre involving DMO eyes of which the initial intervention started between 2010 and 2015, and had been followed for 2 years, were eligible. As interventions, antivascular endothelial growth factor (VEGF) agents, local corticosteroids, macular photocoagulation and vitrectomy were defined. In each eye, baseline and final BCVA, the number of each intervention for 2 years was extracted. Each eye was classified by starting year of interventional treatment.

Results Although baseline BCVA did not change by year, 2-year improvement of BCVA had been increased, and reached to +6.5 letters in the latest term. There is little difference among starting year about proportions of eyes which BCVA gained $>15$ letters, in contrast to those which lost $>15$ letters were decreased by year. The proportion of eyes receiving anti-VEGF therapy was dramatically increased, while those receiving the other therapies were gradually decreased. The proportion of eyes which maintained socially good vision of BCVA $>20 / 40$ has been increased and reached to $59.0 \%$ in the latest term.

Conclusion For recent years, treatment patterns for DMO have been gradually but certainly changed; as a result, better visual gain, suppression of worsened eyes and better final BCVA have been obtained. AntiVEGF therapy has become the first-line therapy and its injection frequency has been increasing.

\section{INTRODUCTION}

Diabetic macular oedema (DMO) is a leading cause of blindness in working age people, with an estimated global prevalence of 21 million individuals. ${ }^{1}$ Although DMO, a frequent microvascular complication, is characterised by vascular leakage and accumulation of extracellular fluid in the macula because of breakdown of the blood-retinal barrier, ${ }^{2}$ the pathophysiology of DMO is complex and involves multiple pathways that lead to central thickening and, if untreated, visual loss. ${ }^{3}$ Thus, several therapeutic modalities have been proposed for the treatment of DMO. Historically, laser photocoagulation was established as the standard treatment for DMO in the $1980 \mathrm{~s},{ }^{4}$ and vitrectomy was introduced in $1990 \mathrm{~s},{ }^{5}$ followed by medical treatment with intravitreal ${ }^{6}$ or posterior subtenon ${ }^{7}$ injection of triamcinolone acetonide (TA) in 2000s. In recent years, the treatment of DMO has changed greatly with the advent of antivascular endothelial growth factor (VEGF) agents. ${ }^{8}$ Large clinical studies demonstrate that the effects of anti-VEGF therapy on DMO are functionally and anatomically superior to those of the other therapies. ${ }^{9-13}$ Although continuous anti-VEGF injections over 2 years improved visual acuity in patients with DMO from 8 to 12 letters ${ }^{14}$ which bring better visual prognosis than the other treatments, a third of patients have an incomplete response to anti-VEGF therapy and thus a multimodal approach has the potential to treat complex aspects of DMO. ${ }^{16}$ In the 'realworld' clinical situations, anti-VEGF agents and other therapies with or without anti-VEGF agents are still being conducted.

The database, Survey of Treatment for DMO (STREAT-DMO), consisted of more than 2000 medical records from a demographically and geographically diverse patient sample in Japan, including all eligible patients who had diagnosed 
Table 1 Patient demographics at initial treatment

\begin{tabular}{|c|c|c|c|c|c|c|c|c|c|}
\hline & Overall & 2010-2012 & 2011-2013 & 2012-2014 & 2013-2015 & 2014-2016 & 2015-2017 & $\begin{array}{l}\text { P value for } \\
\text { ANOVA }\end{array}$ & $\begin{array}{l}\mathrm{P} \text { value for } \\
\text { trend test }\end{array}$ \\
\hline Number of eyes & 2049 & 136 & 285 & 365 & 551 & 468 & 244 & - & - \\
\hline Number of patients & 1552 & 105 & 229 & 258 & 405 & 364 & 191 & - & - \\
\hline Mean age (years)* & $63.5 \pm 10.8$ & $64.8 \pm 10.7$ & $64.0 \pm 10.6$ & $63.3 \pm 11.1$ & $62.3 \pm 11.4$ & $64.6 \pm 10.3$ & $63.0 \pm 9.5$ & 0.033 & 0.547 \\
\hline Sex (male/female) & $989 / 563$ & $63 / 42$ & $139 / 90$ & $166 / 92$ & $252 / 153$ & $247 / 117$ & $122 / 69$ & 0.458 & 0.145 \\
\hline Duration of DM (M)† & $\begin{array}{l}94 \\
(36-168)\end{array}$ & $\begin{array}{l}120 \\
(40-180)\end{array}$ & $\begin{array}{l}120 \\
(60-192)\end{array}$ & $\begin{array}{l}71 \\
(24-132)\end{array}$ & $\begin{array}{l}84 \\
(32-180)\end{array}$ & $\begin{array}{l}96 \\
(36-168)\end{array}$ & $\begin{array}{l}60 \\
(24-120)\end{array}$ & 0.006 & 0.001 \\
\hline $\operatorname{HbA1c}(\%)^{*}$ & $7.7 \pm 1.8$ & $7.5 \pm 1.5$ & $7.6 \pm 1.8$ & $7.6 \pm 1.7$ & $7.9 \pm 2.0$ & $7.6 \pm 1.6$ & $7.7 \pm 1.8$ & 0.170 & 0.425 \\
\hline eGFR $\left(\mathrm{mL} / \mathrm{min} / 1.73 \mathrm{~m}^{2}\right)$ * & $64.8 \pm 27.2$ & $65.2 \pm 27.6$ & $61.9 \pm 23.7$ & $65.9 \pm 30.6$ & $67.1 \pm 28.2$ & $61.3 \pm 25.5$ & $68.1 \pm 26.6$ & 0.176 & 0.657 \\
\hline Cataract surgery & $\begin{array}{l}n=818 \\
(39.9 \%)\end{array}$ & $\begin{array}{l}n=75 \\
(55.1 \%)\end{array}$ & $\begin{array}{l}n=96 \\
(33.7 \%)\end{array}$ & $\begin{array}{l}n=96 \\
(26.3 \%)\end{array}$ & $\begin{array}{l}n=154 \\
(27.9 \%)\end{array}$ & $\begin{array}{l}n=114 \\
(24.4 \%)\end{array}$ & $\begin{array}{l}n=82 \\
(33.6 \%)\end{array}$ & $<0.001$ & $<0.001$ \\
\hline $\begin{array}{l}\text { Photocoagulation outside the } \\
\text { macula }\end{array}$ & $\begin{array}{l}\mathrm{n}=617 \\
(30.1 \%)\end{array}$ & $\begin{array}{l}n=72 \\
(52.9 \%)\end{array}$ & $\begin{array}{l}n=114 \\
(40.0 \%)\end{array}$ & $\begin{array}{l}n=157 \\
(43.0 \%)\end{array}$ & $\begin{array}{l}n=243 \\
(44.1 \%)\end{array}$ & $\begin{array}{l}n=159 \\
(34.0 \%)\end{array}$ & $\begin{array}{l}\mathrm{n}=73 \\
(29.9 \%)\end{array}$ & $<0.001$ & $<0.001$ \\
\hline
\end{tabular}

*Data are provided as mean \pm SD.

tData are provided as median with range.

ANOVA, analysis of variance; DM, diabetes mellitus; eGFR, estimated glomerular filtration rate; HbA1c, glycohaemoglobin.

centre involving DMO without any previous interventions, and started initial treatment for centre involving DMO between January 2010 and December 2015, and had been followed for 2 years. ${ }^{17}$ Within this period, anti-VEGF agents of ranibizumab (February 2014) and aflibercept (November 2014) were approved to DMO in Japan. Thus, treatment patterns for DMO and its visual prognosis must be changed by year, but there were no reports about fluctuation of visual prognosis and intervention required for centre-involving DME by year to year.

In this study, to use this database, fluctuation of treatment patterns and 2-year visual prognosis were analysed and compared among starting year of intervention for DMO.

\section{METHODS}

In this study, all data were obtained from STREAT-DMO database in Japan, previously described. ${ }^{17}$ In brief, this retrospective observational study included all eligible patients who received a diagnosis of treatment-naïve centre involving DMO, started initial treatment between January 2010 and December 2015, and were followed for 2 years (22-26 months). Baseline clinical data obtained from the medical record of each patient included the age, gender, duration of diabetes, glycohaemoglobin and estimated glomerular filtration rate calculated from the creatinine level at initiation of treatment. The best corrected visual acuity (BCVA) determined with a decimal chart and the central macular thickness (CMT) measured by optical coherence tomography (OCT) at the initial and final visits were also extracted from the database. CMT in each eye at baseline and final visit was obtained by the same OCT device. Interventions for each eye during the 2-year period were determined. Centre involving DMO was diagnosed at each institution, and the timing of treatment was decided by each attending physician.

In Japan, ranibizumab was approved for DMO in February 2014, and aflibercept in November 2014. Bevacizumab was off label used before the approval of these two drugs and the treatment regimen of all anti-VEGF agents was decided by each physician. Treatment for DMO was classified as follows: (1) anti-VEGF agents (intravitreal bevacizumab (IVB), ranibizumab (IVR) or aflibercept (IVA)), (2) local corticosteroid (TA) therapy (intravitreal TA (IVTA) or subtenon TA (STTA)), (3) laser photocoagulation of the macular region and (4) vitrectomy. If cataract surgery was performed or laser photocoagulation outside the macular region was done to prevent retinal ischaemia during the 2-year period, this was also recorded because it could influence the visual prognosis.

The study was registered with the University Hospital Medical Information Network individual case data repository (UMIN\#23160).

\section{Clinical evaluation}

To facilitate data analysis, decimal BCVA data were converted to the logarithm of the minimum angle of resolution (logMAR) values or ETDRS equivalent letter scores, as appropriate. ${ }^{18}$ Improvement of BCVA was determined by subtracting the final BCVA from the baseline BCVA. If BCVA increased by more than $0.3 \log$ MAR (15 letters), this was defined as 'improved', while deterioration by more than $0.3 \log$ MAR (15 letters) was defined as 'worsened'. The proportion of eyes with each prognosis was calculated.

The goal of treating DMO is to keep useful BCVA, so the percentage of eyes with a final BCVA better than $0.3 \log$ MAR (20/40 or more on a Snellen chart) was also calculated, since this represents socially useful vision and is defined as 'good' VA; in contrast, BCVA worse than $0.3 \log$ MAR (20/40 or less on the Snellen chart) was defined as 'poor' VA.

\section{Alterations of treatment patterns and visual prognosis by starting year of intervention}

To investigate the alterations of treatment patterns and visual prognosis, eligible eyes were classified by the starting year of interventional treatment. Total number, proportions of each intervention and clinical parameters in each group were extracted. Proportions of each anti-VEGF agents (IVB, IVR and IVA), and injection method of local corticosteroid (IVTA and STTA) were also calculated in each group.

\section{Statistics}

Results are presented as the mean $\pm S D$ or median with IQR. One-way analysis of variance (ANOVA) was used to compare normally distributed continuous variables, while the KruskalWallis H-test was employed to evaluate skewed variables. The $\chi^{2}$ test was used to compare nominal scale variables. Treatment period comparisons were carried out with the paired t-test. Trend test for continuous term was analysed using linear regression model and Cochran-Armitage tests for trend, respectively. A two-tailed $\mathrm{p}$ value $<0.05$ was considered to indicate statistical 
Table 2 Visual and anatomical outcomes for 2 years

\begin{tabular}{|c|c|c|c|c|c|c|c|c|c|}
\hline & Overall & 2010-2012 & 2011-2013 & $2012-2014$ & 2013-2015 & 2014-2016 & 2015-2017 & $\begin{array}{l}\text { P value for } \\
\text { ANOVA }\end{array}$ & $\begin{array}{l}P \text { value for } \\
\text { trend test }\end{array}$ \\
\hline $\begin{array}{l}\text { Baseline BCVA } \\
\text { (logMAR) }\end{array}$ & $0.44 \pm 0.37$ & $0.46 \pm 0.33$ & $0.51 \pm 0.41$ & $0.44 \pm 0.35$ & $0.44 \pm 0.36$ & $0.40 \pm 0.35$ & $0.43 \pm 0.38$ & 0.003 & 0.002 \\
\hline Good/poor (eyes) & $735 / 1314$ & $38 / 98$ & $82 / 203$ & $129 / 236$ & $195 / 356$ & $198 / 270$ & $93 / 151$ & 0.002 & $<0.001$ \\
\hline Final BCVA (logMAR) & $0.40 \pm 0.42$ & $0.49 \pm 0.39$ & $0.45 \pm 0.44$ & $0.44 \pm 0.43$ & $0.41 \pm 0.48$ & $0.33 \pm 0.35$ & $0.30 \pm 0.36$ & $<0.001$ & $<0.001$ \\
\hline Good/poor (eyes) & $949 / 1100$ & $48 / 88$ & $119 / 166$ & $140 / 225$ & $256 / 295$ & $242 / 226$ & $144 / 100$ & $<0.001$ & $<0.001$ \\
\hline Difference of BCVA & $-0.04 \pm 0.40$ & $0.03 \pm 0.41$ & $-0.06 \pm 0.38$ & $0.00 \pm 0.43$ & $-0.03 \pm 0.45$ & $-0.07 \pm 0.34$ & $-0.13 \pm 0.31$ & $<0.001$ & $<0.001$ \\
\hline$P$ value & $<0.001$ & 0.3527 & 0.0055 & 0.9523 & 0.1107 & $<0.001$ & $<0.001$ & - & - \\
\hline $95 \% \mathrm{Cl}(\log \mathrm{MAR})$ & -0.0622 to -0.0278 & -0.0372 to 0.1035 & -0.1078 to -0.0188 & -0.0427 to 0.0454 & -0.0680 to 0.0070 & -0.0978 to -0.0361 & -0.1658 to -0.0884 & - & - \\
\hline Baseline CMT ( $\mu \mathrm{m})$ & $443.8 \pm 154.8$ & $435.7 \pm 165.8$ & $447.3 \pm 155.9$ & $456.1 \pm 158.1$ & $446.1 \pm 161.1$ & $441.1 \pm 151.5$ & $425.9 \pm 131.8$ & 0.279 & 0.180 \\
\hline Final CMT $(\mu \mathrm{m})$ & $335.6 \pm 139.6$ & $347.9 \pm 158.3$ & $335.5 \pm 134.4$ & $354.0 \pm 151.8$ & $327.3 \pm 149.3$ & $331.3 \pm 130.4$ & $328.9 \pm 104.6$ & 0.070 & 0.059 \\
\hline $\begin{array}{l}\text { Difference of CMT } \\
(\mu \mathrm{m})\end{array}$ & $-108.2 \pm 186.8$ & $-87.8 \pm 213.6$ & $-111.8 \pm 192.1$ & $-102.1 \pm 198.9$ & $-118.8 \pm 186.2$ & $-109.8 \pm 183.5$ & $-97.1 \pm 150.7$ & 0.456 & 0.766 \\
\hline$P$ value & $<0.001$ & $<0.001$ & $<0.001$ & $<0.001$ & $<0.001$ & $<0.001$ & $<0.001$ & - & - \\
\hline $95 \% \mathrm{Cl}(\log M A R)$ & -116.3 to -100.0 & -124.9 to -50.7 & -134.7 to -88.9 & -122.7 to -81.5 & -134.5 to -103.1 & -126.5 to -93.1 & -116.1 to -78.0 & - & - \\
\hline
\end{tabular}

Data were presented as mean value $\pm S D$

ANOVA, analysis of variance; BCVA, best corrected visual acuity; CMT, central macular thickness.

significance. Analyses were performed with SAS V.9.4 TS1M5 (SAS Institute) and were carried out by an independent biostatistics data centre (STATZ Institute, Tokyo, Japan).

\section{RESULTS}

Patient characteristics classified by 2-year observation period are listed in table 1 . It is noteworthy that proportions of history of cataract surgery and photocoagulation outside the macula were higher in term 2010-2012 than the other periods $(\mathrm{p}<0.001$ by ANOVA), and tended to decrease each year $(\mathrm{p}<0.001$ by trend test).

Visual and anatomical outcome for 2-year period in each term are listed in table 2. There were significant tendencies to be better by year about both baseline BCVA $(p=0.002$ by trend test; figure $1 \mathrm{~A}$ filled square) and final BCVA $(\mathrm{p}<0.001$ by trend test; figure 1A open square). Furthermore, averaged improvement of BCVA also showed tendency to be better by year $(p<0.001$ by trend test; figure $1 \mathrm{~B}$ ). Interestingly, baseline BCVA in term 2011-2013 was worse than the other term, and improvement of BCVA in this term showed relatively good. While CMT in each starting year group showed statistically significant reduction, however there were no significant tendencies of baseline, final and difference of CMT by year.

Proportions of 'improved' eyes which gained $>0.3 \operatorname{logMAR}$ for 2 years were slightly increased by year $(p=0.02$ by trend test; figure 2A filled rhombus), in contrast to those of worsened eyes which lost $>0.3 \log$ MAR showed tendency to decrease ( $p<0.001$ by trend test; figure $2 \mathrm{~A}$ open rhombus). Proportions of eyes which maintained 'good' final BCVA > 20/40 were gradually increased by year ( $\mathrm{p}<0.001$ by trend test; figure $2 \mathrm{~B}$ ).

Treatment patterns and averaged frequency of each treatment for 2 years were listed in table 3. Proportion of eyes which received anti-VEGF therapy was increased by year $(p<0.001$ by trend test), but that received corticosteroid was not changed by year $(p=0.137$ by trend test) while proportions of eyes which received macular photocoagulation and vitrectomy were decreased by year $(\mathrm{p}<0.001$ by trend test; figure 3$)$.

Proportion of eyes which received IVB in anti-VEGF therapy was dramatically decreased ( $\mathrm{p}<0.001$ by trend test), in contrast to those which received IVR and IVA were increased by year $(\mathrm{p}<0.001$ by trend test; figure 4A).

Proportions of eyes which received IVTA and STTA did not affect by year $(p=0.446, p=0.094$ by trend test). Regardless of the observational term, STTA was conducted in most cases of local corticosteroid therapy (figure 4B).

Averaged required number of each intervention for 2 years in each term was listed in table 3. Required number of anti-VEGF agents were dramatically increased by year $(p<0.001$ by trend test), in contrast to those of corticosteroid, macular photocoagulation and vitrectomy did not affect by year $(\mathrm{p}=0.517, \mathrm{p}=0.339, \mathrm{p}=0.221$ by
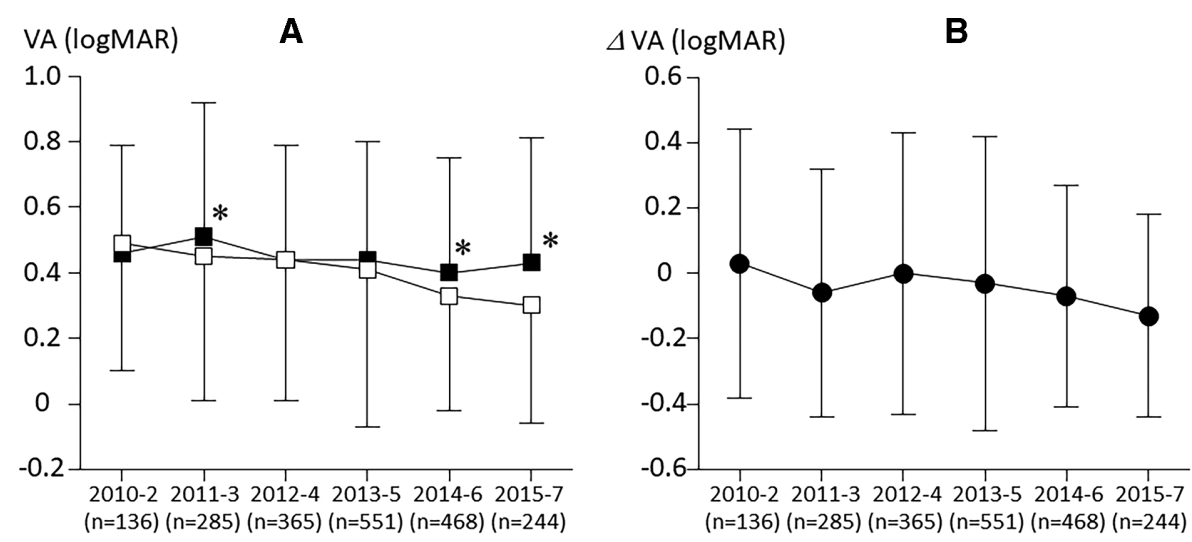

Figure 1 (A) Alterations of averaged baseline best corrected visual acuity (BCVA) (black square) and final BCVA (white square) according to the 2-year term by starting year to final year. (B) Alteration of improvement of BCVA according to the 2-year term (black circle). Each vertical bar indicates SD of the mean. Each asterisk indicates statistically significant difference between baseline and final BCVA in each term. 

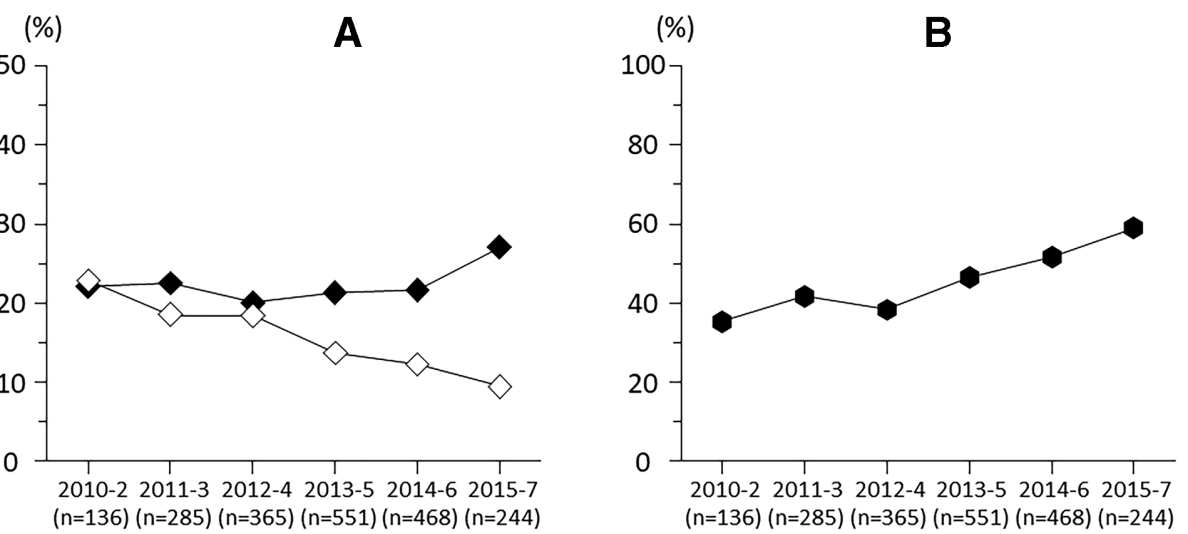

Figure 2 (A) Alterations of proportions of eyes with >15 letters gaining from baseline (black rhombus: \%) and proportions of eyes with >15 letters worsening from baseline (white rhombus: \%). (B) Alteration of proportions of eyes having 'good' final best corrected visual acuity $>20 / 40$ (black hexagon: \%).

trend test; figure 5A). As to anti-VEGF agents, required number of IVB was 2-3 times regardless of starting year, in contrast, those of IVR and IVA simply increased by year (figure 5B).

\section{DISCUSSION}

According to results of this study, treatment patterns for DMO were found to have been changed in recent years; proportion of eyes which received anti-VEGF therapy has been increased, in contrast to those received macular photocoagulation and vitrectomy has been decreased by year. Improvement of BCVA for 2 years of intervention to DMO was gradually better, and the percentage of eyes with final BCVA better than 20/40 were also gradually higher by year. In contrast, anatomical regression of CMT was not influenced by treatment pattern and starting year of intervention. Previous study results suggested that CMT cannot substitute reliably as a surrogate for visual acuity. ${ }^{19}$ In this study, although it should be handled carefully because each CMT was measured with different instrument, anatomical regression of DMO was also found not to be related to functional improvement.

\section{Alterations of visual prognosis by year}

According to our study results, improvement of BCVA for 2 years after the initial intervention in each term tended to be better by year. Considering the fact that both baseline and final BCVA showed tendency to be better by year, improvement of BCVA seems to have been affected by the changes of treatment patterns

Table 3 Treatment frequency and its number of eyes

\begin{tabular}{|c|c|c|c|c|c|c|c|c|c|}
\hline & Overall & 2010-2012 & 2011-2013 & 2012-2014 & 2013-2015 & 2014-2016 & 2015-2017 & $P$ value for ANOVA & $P$ value for trend test \\
\hline Anti-VEGF & $\begin{array}{l}n=1234 \\
(60.2 \%)\end{array}$ & $\begin{array}{l}n=80 \\
(58.8 \%)\end{array}$ & $\begin{array}{l}n=107 \\
(37.5 \%)\end{array}$ & $\begin{array}{l}n=201 \\
(55.1 \%)\end{array}$ & $\begin{array}{l}n=324 \\
(58.8 \%)\end{array}$ & $\begin{array}{l}n=343 \\
(73.3 \%)\end{array}$ & $\begin{array}{l}n=179 \\
(73.4 \%)\end{array}$ & $<0.001$ & $<0.001$ \\
\hline Number of times & $3.8 \pm 3.3$ & $2.5 \pm 1.8$ & $1.8 \pm 1.5$ & $2.9 \pm 2.7$ & $3.5 \pm 3.0$ & $4.7 \pm 3.7$ & $5.5 \pm 3.6$ & $<0.001$ & $<0.001$ \\
\hline Bevacizumab & $\begin{array}{l}n=635 \\
(31.0 \%)\end{array}$ & $\begin{array}{l}n=80 \\
(58.8 \%)\end{array}$ & $\begin{array}{l}n=103 \\
(36.1 \%)\end{array}$ & $\begin{array}{l}n=180 \\
(49.3 \%)\end{array}$ & $\begin{array}{l}n=224 \\
(40.7 \%)\end{array}$ & $\begin{array}{l}n=37 \\
(7.9 \%)\end{array}$ & $\begin{array}{l}n=11 \\
(4.5 \%)\end{array}$ & $<0.001$ & $<0.001$ \\
\hline Number of times & $2.2 \pm 2.0$ & $2.5 \pm 1.7$ & $1.6 \pm 0.9$ & $2.4 \pm 2.3$ & $2.4 \pm 2.2$ & $1.9 \pm 1.3$ & $1.3 \pm 0.5$ & 0.003 & 0.969 \\
\hline Ranibizumab & $\begin{array}{l}n=578 \\
(28.2 \%)\end{array}$ & $\begin{array}{l}\mathrm{n}=2 \\
(1.5 \%)\end{array}$ & $\begin{array}{l}n=4 \\
(1.4 \%)\end{array}$ & $\begin{array}{l}n=44 \\
(12.1 \%)\end{array}$ & $\begin{array}{l}n=152 \\
(27.6 \%)\end{array}$ & $\begin{array}{l}n=284 \\
(60.7 \%)\end{array}$ & $\begin{array}{l}n=92 \\
(37.7 \%)\end{array}$ & $<0.001$ & $<0.001$ \\
\hline Number of times & $3.3 \pm 2.8$ & 1.0 & $1.0 \pm 0.0$ & $2.1 \pm 1.6$ & $2.9 \pm 2.3$ & $3.4 \pm 3.1$ & $4.2 \pm 2.8$ & $<0.001$ & $<0.001$ \\
\hline Aflibercept & $\begin{array}{l}n=336 \\
(16.4 \%)\end{array}$ & $\begin{array}{l}n=1 \\
(0.7 \%)\end{array}$ & $\begin{array}{l}n=4 \\
(1.4 \%)\end{array}$ & $\begin{array}{l}n=14 \\
(3.8 \%)\end{array}$ & $\begin{array}{l}n=69 \\
(12.5 \%)\end{array}$ & $\begin{array}{l}n=139 \\
(29.7 \%)\end{array}$ & $\begin{array}{l}n=109 \\
(44.7 \%)\end{array}$ & $<0.001$ & $<0.001$ \\
\hline Number of times & $4.1 \pm 3.0$ & 2.0 & $5.0 \pm 4.1$ & $3.5 \pm 2.8$ & $2.4 \pm 1.9$ & $4.0 \pm 2.9$ & $5.4 \pm 3.3$ & $<0.001$ & $<0.001$ \\
\hline Corticosteroid & $\begin{array}{l}n=1077 \\
(52.6 \%)\end{array}$ & $\begin{array}{l}n=66 \\
(48.5 \%)\end{array}$ & $\begin{array}{l}n=145 \\
(50.9 \%)\end{array}$ & $\begin{array}{l}n=195 \\
(53.4 \%)\end{array}$ & $\begin{array}{l}n=345 \\
(62.6 \%)\end{array}$ & $\begin{array}{l}n=220 \\
(47.0 \%)\end{array}$ & $\begin{array}{l}n=106 \\
(43.4 \%)\end{array}$ & $<0.001$ & 0.137 \\
\hline Number of times & $2.0 \pm 1.3$ & $1.9 \pm 1.2$ & $2.0 \pm 1.3$ & $2.1 \pm 1.3$ & $2.0 \pm 1.4$ & $2.2 \pm 1.4$ & $1.7 \pm 1.1$ & 0.097 & 0.517 \\
\hline Intravitreal TA & $\begin{array}{l}n=162 \\
(7.9 \%)\end{array}$ & $\begin{array}{l}n=8 \\
(5.9 \%)\end{array}$ & $\begin{array}{l}n=4 \\
(1.4 \%)\end{array}$ & $\begin{array}{l}n=42 \\
(11.5 \%)\end{array}$ & $\begin{array}{l}n=66 \\
(12.0 \%)\end{array}$ & $\begin{array}{l}n=28 \\
(6.0 \%)\end{array}$ & $\begin{array}{l}n=14 \\
(5.7 \%)\end{array}$ & $<0.001$ & 0.466 \\
\hline Number of times & $1.7 \pm 1.1$ & $1.4 \pm 0.7$ & $2.0 \pm 0.8$ & $1.5 \pm 0.7$ & $1.6 \pm 1.2$ & $2.4 \pm 1.5$ & $1.7 \pm 1.1$ & 0.014 & 0.034 \\
\hline Subtenon TA & $\begin{array}{l}n=966 \\
(47.1 \%)\end{array}$ & $\begin{array}{l}n=62 \\
(45.6 \%)\end{array}$ & $\begin{array}{l}n=144 \\
(50.5 \%)\end{array}$ & $\begin{array}{l}n=167 \\
(45.8 \%)\end{array}$ & $\begin{array}{l}n=288 \\
(52.3 \%)\end{array}$ & $\begin{array}{l}n=205 \\
(43.8 \%)\end{array}$ & $\begin{array}{l}n=100 \\
(41.0 \%)\end{array}$ & 0.020 & 0.094 \\
\hline Number of times & $2.0 \pm 1.3$ & $1.9 \pm 1.2$ & $2.0 \pm 1.2$ & $2.0 \pm 1.4$ & $2.1 \pm 1.3$ & $2.0 \pm 1.2$ & $1.6 \pm 1.0$ & 0.022 & 0.117 \\
\hline Macular PC & $\begin{array}{l}n=746 \\
(36.4 \%)\end{array}$ & $\begin{array}{l}n=40 \\
(29.4 \%)\end{array}$ & $\begin{array}{l}n=122 \\
(42.8 \%)\end{array}$ & $\begin{array}{l}n=141 \\
(38.6 \%)\end{array}$ & $\begin{array}{l}n=236 \\
(42.8 \%)\end{array}$ & $\begin{array}{l}n=154 \\
(32.9 \%)\end{array}$ & $\begin{array}{l}n=53 \\
(21.7 \%)\end{array}$ & $<0.001$ & $<0.001$ \\
\hline Number of times & $1.9 \pm 1.4$ & $1.7 \pm 1.1$ & $1.9 \pm 1.4$ & $2.0 \pm 1.4$ & $1.8 \pm 1.3$ & $2.0 \pm 1.6$ & $1.3 \pm 0.6$ & 0.010 & 0.339 \\
\hline Vitrectomy & $\begin{array}{l}n=597 \\
(29.1 \%)\end{array}$ & $\begin{array}{l}n=64 \\
(47.1 \%)\end{array}$ & $\begin{array}{l}n=125 \\
(43.9 \%)\end{array}$ & $\begin{array}{l}n=115 \\
(31.5 \%)\end{array}$ & $\begin{array}{l}n=148 \\
(26.9 \%)\end{array}$ & $\begin{array}{l}n=76 \\
(16.2 \%)\end{array}$ & $\begin{array}{l}n=69 \\
(28.3 \%)\end{array}$ & $<0.001$ & $<0.001$ \\
\hline Number of times & $1.1 \pm 0.3$ & $1.1 \pm 0.3$ & $1.1 \pm 0.3$ & $1.1 \pm 0.2$ & $1.0 \pm 0.2$ & $1.0 \pm 0.2$ & $1.1 \pm 0.2$ & 0.558 & 0.221 \\
\hline
\end{tabular}

Data about number of times were presented as mean value $\pm S D$.

ANOVA, analysis of variance; PC, photocoagulation; TA, triamcinolone acetonide; VEGF, vascular endothelial growth factor. 
(\%)

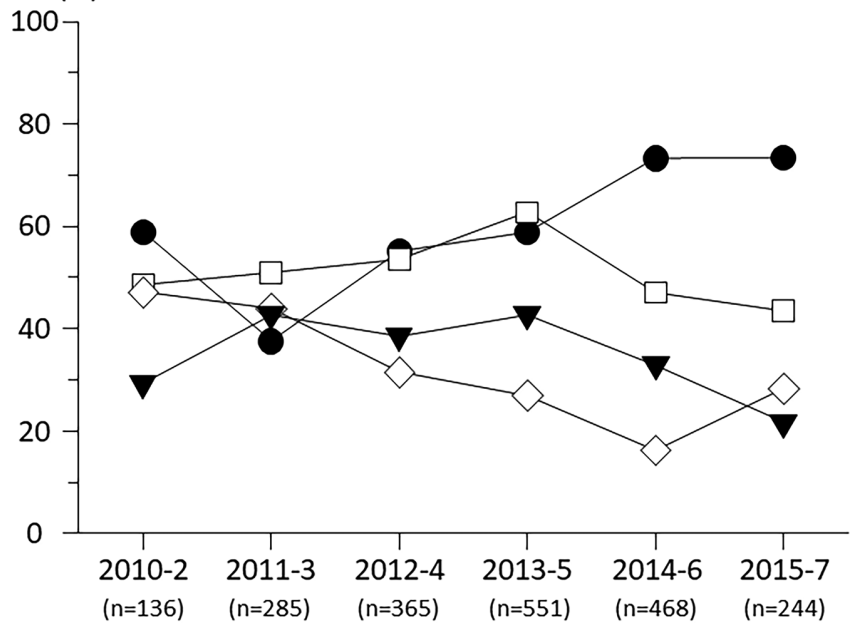

Figure 3 Alterations of proportions of eyes which received antivascular endothelial growth factor agents (black circle), local corticosteroids (white square), macular photocoagulation (black triangle) and vitrectomy (white rhombus).

for DMO, indicating that the treatment options by retina specialists have become effective by year. Although it remains unclear the reason why the term of 2011-2013 alone is out of this trend, baseline BCVA in this term was statistically worse than in the other term; therefore, it is likely to be caused by a ceiling effect (eyes with good BCVA at baseline had less vision to gain to return to normal vision, making very large improvements impossible). ${ }^{20}$

In this study, averaged baseline BCVA of 0.44 (0.40-0.51) $\log$ MAR which is converted to 63 (59-65) letters was almost the same as those in previous clinical trials, whose averaged baseline BCVA was 62.4-64.8 letters in RESTORE study, 58.8-60.8 letters in VIVID/VISTA studies. ${ }^{11}$ Even a latest improvement of BCVA in this study which was $-0.13 \log$ MAR $(+6.5$ letters $)$ did not reach to clinical trials of $+6.7-7.9$ letters, ${ }^{12}$ or $+11.1-11.5$ letters. ${ }^{11}$ In these clinical trials, averaged number of anti-VEGF drug injection for 2 years was $14.5-15.2$ times, ${ }^{12}$ or $13.5-22.6$ times, ${ }^{11}$ while the latest averaged injection number in our study was 5.5 times, and $26.6 \%$ of DMO eyes did not receive anti-VEGF therapy.

The proportion of worsened eyes decreased by year, while those of improved eyes did not change much. The yearly alterations of treatment patterns seem to have rescued the worsened eyes. In the latest term of 2015-2017, there were $27.0 \%$ of improved and 9.4\% of worsened eyes, which is still less than the previous reports in RESTORE study ${ }^{12}(\approx 25.0 \%$ of improved, and $\approx 1 \%$ of worsened eyes), or in VIVID/VISTA studies ${ }^{11}$ $(\approx 35.0 \%$ of improved, and $\approx 2 \%$ of worsened eyes). More proportions and more injection number of anti-VEGF agents may lead suppression of worsened eyes.

Treating DMO eyes according to regularly administration of anti-VEGF agents probably produce the best possible visual prognosis, but treatment is expensive and compliance is difficult to maintain. Our real-world data indicated that there still remained room to devise treatment options for DMO.

The optimal goal of treatment for DMO is to achieve good visual acuity of $20 / 40$ or more after any interventions. ${ }^{21}$ According to the other real-world study of anti-VEGF treatment for DMO results, 51.9\%-62.3\% patients achieved $>20 / 40$ BCVA. $^{22}$ In our study, the proportion of eyes which maintained final $>20 / 40$ BCVA is increased and reached to $59.0 \%$ in the latest term of 2015-2017. Even in this period, $26.6 \%$ of eyes did not receive anti-VEGF agents during the clinical course.

\section{Alterations of treatment patterns by year}

According to our data set, treatment patterns for DMO were changed by year. Especially, in the term of 2014-2016, and 2015-2017, proportion of anti-VEGF therapy was dramatically increased. In Japan, ranibizumab, a humanised anti-VEGF monoclonal antibody Fab fragment that binds to VEGF-A, ${ }^{10}$ and aflibercept, a fusion glycoprotein consisting of the extracellular domain of VEGF receptors 1 and 2 fused to the Fc domain of human IgG1 that binds to VEGF-A, VEGF-B and placental growth factor ${ }^{11}$ was approved in February and November 2014. Thus, in the last two terms, retina specialists must not hesitate to apply anti-VEGF agents.

While, corticosteroid therapy which is usually applied as STTA regardless of the starting year in Japan had been applied to half of DMO eyes. In contrast, macular photocoagulation and vitrectomy tended to reduce each year. These interventions were likely to have been replaced by anti-VEGF therapy.

Recently, anti-VEGF therapy is recommended as the first-line therapy for centre involving DMO, which is a leading cause of vision impairment, ${ }^{23} 24$ while not a few patients were found to be inconsistent or non-responsive to anti-VEGF agents ${ }^{25} 26$ and retina specialists still debate about the best second-line
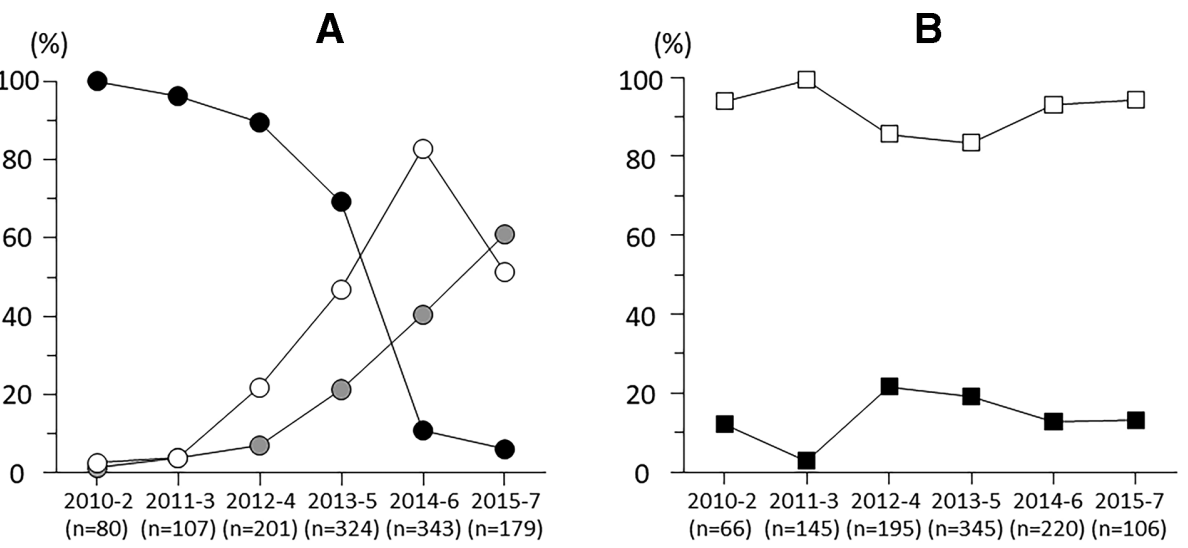

Figure 4 (A) Alterations of proportions of eyes which received bevacizumab (black circle), ranibizumab (white circle) or aflibercept (grey circle) to eyes which received antivascular endothelial growth factor agents. (B) Alterations of proportions of eyes which received as intravitreal (black square) or subtenon (white square) injection to eyes which received local corticosteroids. 

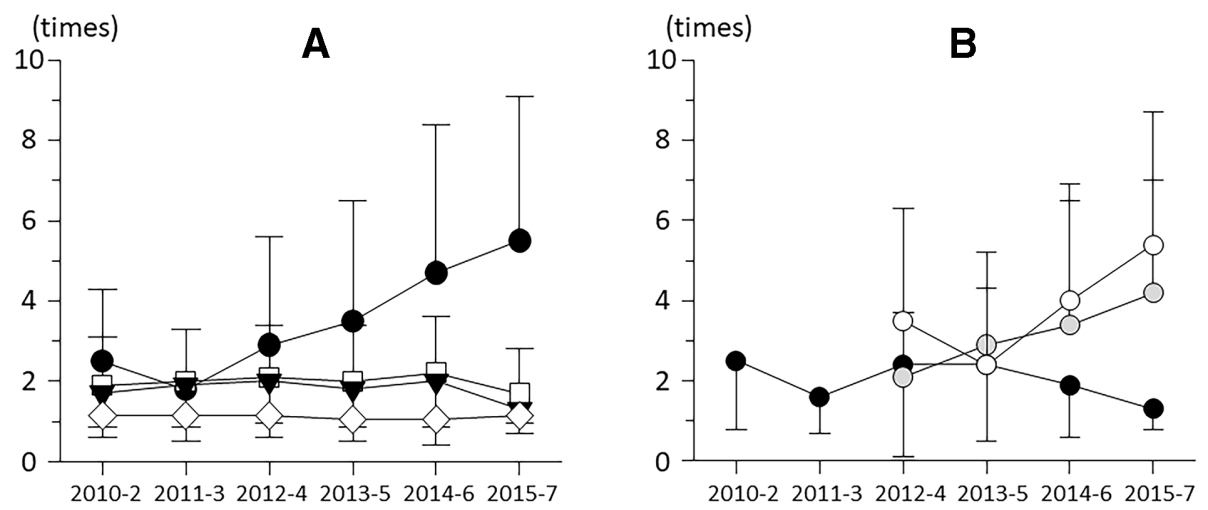

Figure 5 (A) Alterations of averaged required number of interventions for 2 years, which was antivascular endothelial growth factor (VEGF) agents (black circle), local corticosteroids (white square), macular photocoagulation (black triangle) and vitrectomy (white rhombus). (B) Alterations of averaged required number of each anti-VEGF agent for 2 years, as bevacizumab (black circle), ranibizumab (white circle) and aflibercept (grey circle). Note that ranibizumab and aflibercept had been approved since 2014; thus, these data on first two terms were omitted.

therapy. As a second-line therapy, corticosteroid is considered to be effective for chronic DMO, ${ }^{27}$ and macular photocoagulation is agreed as an excellent treatment for centre threatening DMO with good vision. ${ }^{4}$ Vitrectomy may be expected as alternative therapy for persistent DMO which resisted to the other therapies despite that the efficacy of vitrectomy for DMO remains uncertain. ${ }^{28}$

Before 2014 in the absence of approved anti-VEGF agents, bevacizumab, an off-labelled, humanised anti-VEGF monoclonal antibody ${ }^{29}$ was widely used with fewer (1.8-2.9) injections. Among large prospective clinical trials that evaluated the efficacy and safety of ranibizumab and bevacizumab treatment in patients with DMO, the largest gains in BCVA were seen in trials that used the most frequent (monthly) administration of anti-VEGF. These results suggest a correlation between the frequency of anti-VEGF injections and efficacy. ${ }^{30}$ Annual increase of frequency of anti-VEGF injections may be involved in better visual prognosis, and in the latest periods, retina specialists in Japan positively tended to use ranibizumab and aflibercept with a greater number of injections. In contrast, treatment frequency of other therapies was less than two times per 2 years and did not change by treatment term. Thus, both proportions of anti-VEGF therapy and its frequency were increased by year and cause better 2-year visual prognosis for DMO. More recently, comparison of efficacy for visual prognosis among aflibercept, ranibizumab and bevacizumab was investigated, and superiority of aflibercept for DMO eyes with worse baseline BCVA was reported. ${ }^{31} 32$ In this study, increased proportion and frequency of aflibercept by year may also have contributed to better 2-year visual prognosis for DMO.

Different form randomised controlled trials which assess the effectivity of certain treatment interventions under controlled conditions, real-world studies provide information on the clinical results under real-world conditions. To conduct realworld studies, data collection must be cared, however were usually performed automatically from electronic medical records ${ }^{21} 33$ or extracted from public healthcare systems. ${ }^{34} 35$ In our STREAT-DMO database, apart from these previous retrospective studies, submitted data from each institution were collected in the statistics centre, and manually checked and carefully reviewed one by one by numerous investigators. Also in our database, clinical course in each eye was limited to 2 years; thus, it was possible to compare the visual prognosis among starting year of intervention. Although real-world data have numerous limitations, results can be better generalised to typical clinical practice. ${ }^{36}$ According to our study results, application of anti-VEGF therapy to treatment-naïve DMO eyes and its frequency has been increased year by year; as a result, visual prognosis, especially as decreasing worsened eyes, has been better in Japan. In future, mimic study should be required to compare with our current yearly information.

\section{Author affiliations}

${ }^{1}$ Department of Ophthalmology, Tokyo Medical University Hachioji Medical Center, Hachioji, Tokyo, Japan

${ }^{2}$ Diabetes Center, Tokyo Women's Medical University School of Medicine, Shinjukuku, Tokyo, Japan

${ }^{3}$ Department of Ophthalmology, Tokyo Medical University, Shinjuku-ku, Tokyo, Japan ${ }^{4}$ Department of Ophthalmology, University of Fukui, Yoshida, Japan

${ }^{5}$ Department of Ophthalmology, Nagasaki University School of Medicine Graduate School of Biomedical Sciences, Nagasaki, Japan

${ }^{6}$ Department of Ophthalmology, Wakayama Medical University, Wakayama, Japan ${ }^{7}$ Department of Ophthalmology, St. Marianna University School of Medicine,

Kawasaki, Kanagawa, Japan

${ }^{8}$ Department of Ophthalmology, Tachikawa Hospital, Tachikawa, Japan

${ }^{9}$ Department of Ophthalmology, National Hospital Organisation Tokyo Medical Center, Meguro-ku, Tokyo, Japan

${ }^{10}$ Department of Ophthalmology, Okayama University Graduate School of Medicine, Dentistry and Pharmaceutical Sciences, Okayama, Japan

${ }^{11}$ Kyorin Eye Center, Kyorin University School of Medicine, Mitaka, Tokyo, Japan

${ }^{12}$ Department of Ophthalmology, Kagoshima University Graduate School of Medical and Dental Sciences, Kagoshima, Japan

${ }^{13}$ Deparment of Ophthalmology, Shinshu University School of Medicine, Matsumoto, Nagano, Japan

${ }^{14}$ Department of Ophthalmology, Hyogo College of Medicine, Nishinomiya, Hyogo, Japan

${ }^{15}$ Department of Ophthalmology, Institute of Biomedical Sciences, Tokushima

University Graduate School, Tokushima, Tokushima, Japan

${ }^{16}$ Department of Ophthalmology, University of Tsukuba Faculty of Medicine, Tsukuba, Ibaraki, Japan

${ }^{17}$ Department of Ophthalmology, Sapporo City General Hospital, Sapporo, Japan

${ }^{18}$ Department of Ophthalmology, Yamaguchi University Graduate School of Medicine, Ube, Yamaguchi, Japan

${ }^{19}$ Department of Ophthalmology, Mie University Graduate School of Medicine, Tsu, Mie, Japan

${ }^{20}$ Department of Ophthalmology, Japanese Red Cross Otsu Hospital, Otsu, Japan

${ }^{21}$ Department of Ophthalmology, Hirosaki University School of Medicine Graduate

School of Medicine, Hirosaki, Aomori, Japan

${ }^{22}$ Hikichi Eye Clinic, Sapporo, Hokkaido, Japan

${ }^{23}$ Department of Ophthalmology, Showa General Hospital, Kodaira, Tokyo, Japan

${ }^{24}$ Department of Ophthalmology, National Defense Medical College, Tokorozawa

Saitama, Japan

${ }^{25}$ Department of Ophthalmology, St. Luke's International Hospital, Tokyo, Japan

${ }^{26}$ Department of Ophthalmology, Nara Medical University, Kashihara, Nara, Japan 
${ }^{27}$ Department of Surgery Related, Division of Ophthalmology, Kobe University Graduate School of Medicine, Kobe, Japan

Collaborators Japan Clinical Retina Study (J-CREST) group: Statistical analysis: Katsunori Shimada PhD in STATZ Institute Inc. Contributions of the authors by data acquisition: Hidetaka Noma MD, Ryosuke Motohashi MD, Osamu Kotake MD and Makoto Imazeki MD in Department of Ophthalmology, Tokyo Medical University, Hachioji Medical Center. Eiko Tsuzuki MD in Department of Ophthalmology and Visual Sciences, Graduate School of Biomedical Sciences, Nagasaki University. Shizuya Saika MD in Department of Ophthalmology, Wakayama Medical University. Ryutaro Yamanishi MD in Department of Ophthalmology, National Tokyo Medical Center. Takao Kashiwagi MD and Fumi Gomi MD in Department of Ophthalmology, Hyogo College of Medicine. Takashi Katome MD in Department of Ophthalmology, Institute of Biomedical Sciences, Tokushima University Graduate School. Keiichi Nishikawa MD in Department of Ophthalmology, Japanese Red Cross Otsu Hospital. Mitsuru Nakazawa MD in Department of Ophthalmology, Hirosaki University Graduate School of Medicine. Masaru Takeuchi MD in Department of Ophthalmology, National Defense Medical College. Nahoko Ogata MD in Department of Ophthalmology, Nara Medical University.

Funding This study was supported by clinical research grant-in aid by Tokyo Medical University. This study is registered with the University Hospital Medical Information Network individual case data repository (UMIN\#23160).

Competing interests None declared.

Patient consent for publication Not required.

Ethics approval The study protocol was reviewed and approved by the Institutional Review Board of each participating centre.

Provenance and peer review Not commissioned; externally peer reviewed.

Data availability statement Data are available upon reasonable request. All data were stored and managed in a statistical institution and available upon reasonable request.

Open access This is an open access article distributed in accordance with the Creative Commons Attribution Non Commercial (CC BY-NC 4.0) license, which permits others to distribute, remix, adapt, build upon this work non-commercially, and license their derivative works on different terms, provided the original work is properly cited, appropriate credit is given, any changes made indicated, and the use is non-commercial. See: http://creativecommons.org/licenses/by-nc/4.0/.

\section{ORCID iDs}

Masahiko Shimura http://orcid.org/0000-0001-5456-6374

Yoshinori Mitamura http://orcid.org/0000-0002-4813-672X

Kazuhiro Kimura http://orcid.org/0000-0002-2502-6149

Kenji Yamashiro http://orcid.org/0000-0001-9354-8558

Taiji Sakamoto http://orcid.org/0000-0003-0287-3801

\section{REFERENCES}

1 Yau JWY, Rogers SL, Kawasaki R, et al. Global prevalence and major risk factors of diabetic retinopathy. Diabetes Care 2012;35:556-64.

2 Das A, McGuire PG, Rangasamy S. Diabetic macular edema: pathophysiology and novel therapeutic targets. Ophthalmology 2015;122:1375-94.

3 Barham R, El Rami H, Sun JK, et al. Evidence-Based treatment of diabetic macular edema. Semin Ophthalmol 2017:32:56-66.

4 Photocoagulation for diabetic macular edema. early treatment diabetic retinopathy study report number 1. early treatment diabetic retinopathy study Research Group. Arch Ophthalmol 1985;103:1796-806.

5 Lewis H, Abrams GW, Blumenkranz MS, et al. Vitrectomy for diabetic macular traction and edema associated with posterior hyaloidal traction. Ophthalmology 1992:99:753-9.

6 Jonas JB, Kreissig I, Söfker A, et al. Intravitreal injection of triamcinolone for diffuse diabetic macular edema. Arch Ophthalmol 2003;121:57-61.

7 Verma LK, Vivek MB, Kumar A, et al. A prospective controlled trial to evaluate the adjunctive role of posterior subtenon triamcinolone in the treatment of diffuse diabetic macular edema. J Ocul Pharmacol Ther 2004;20:277-84.

8 Stewart MW. Anti-VEGF therapy for diabetic macular edema. Curr Diab Rep 2014;14:510

9 Elman MJ, Ayala A, Bressler NM, et al. Intravitreal ranibizumab for diabetic macular edema with prompt versus deferred laser treatment: 5 -year randomized trial results. Ophthalmology 2015;122:375-81.

10 Ishibashi T, Li X, Koh A, et al. The reveal study: ranibizumab monotherapy or combined with laser versus laser monotherapy in Asian patients with diabetic macular edema. Ophthalmology 2015;122:1402-15.

11 Korobelnik J-F, Do DV, Schmidt-Erfurth U, et al. Intravitreal aflibercept for diabetic macular edema. Ophthalmology 2014;121:2247-54.
12 Mitchell P, Bandello F, Schmidt-Erfurth U, et al. The restore study: ranibizumab monotherapy or combined with laser versus laser monotherapy for diabetic macular edema. Ophthalmology 2011;118:615-25.

13 Nguyen QD, Brown DM, Marcus DM, et al. Ranibizumab for diabetic macular edema: results from 2 phase III randomized trials: RISE and RIDE. Ophthalmology 2012;119:789-801.

14 Heier JS, Korobelnik J-F, Brown DM, et al. Intravitreal aflibercept for diabetic macular edema: 148-Week results from the VISTA and VIVID studies. Ophthalmology 2016;123:2376-85.

15 Lang GE, Berta A, Eldem BM, et al. Two-Year safety and efficacy of ranibizumab 0.5 $\mathrm{Mg}$ in diabetic macular edema: interim analysis of the RESTORE extension study. Ophthalmology 2013:120:2004-12.

16 Terasaki H, Ogura Y, Kitano S, et al. Management of diabetic macular edema in Japan: a review and expert opinion. Jpn J Ophthalmol 2018;62:1-23.

17 Shimura M, Kitano S, Muramatsu D, et al. Real-World management of treatmentnaïve diabetic macular oedema in Japan: two-year visual outcomes with and without anti-VEGF therapy in the STREAT-DME study. Br J Ophthalmol 2019. doi:10.1136/ bjophthalmol-2019-315199. [Epub ahead of print: 29 Nov 2019].

18 Gregori NZ, Feuer W, Rosenfeld PJ. Novel method for analyzing Snellen visual acuity measurements. Retina 2010;30:1046-50.

19 Browning DJ, Glassman AR, Aiello LP, et al. Relationship between optical coherence tomography-measured central retinal thickness and visual acuity in diabetic macular edema. Ophthalmology 2007;114:525-36.

20 Sophie R, Lu N, Campochiaro PA. Predictors of functional and anatomic outcomes in patients with diabetic macular edema treated with ranibizumab. Ophthalmology 2015;122:1395-401.

21 Egan C, Zhu H, Lee A, et al. The United Kingdom diabetic retinopathy electronic medical record users group, report 1: baseline characteristics and visual acuity outcomes in eyes treated with intravitreal injections of ranibizumab for diabetic macular oedema. Br J Ophthalmol 2017;101:75-80.

22 Blinder KJ, Dugel PU, Chen S, et al. Anti-VEGF treatment of diabetic macular edema in clinical practice: effectiveness and patterns of use (ECHO study report 1). Clin Ophthalmol 2017:11:393-401.

23 Bandello F, Cunha-Vaz J, Chong NV, et al. New approaches for the treatment of diabetic macular oedema: recommendations by an expert panel. Eye 2012;26:485-93.

24 Mitchell P, Wong TY, Diabetic Macular Edema Treatment Guideline Working Group. Management paradigms for diabetic macular edema. Am J Ophthalmol 2014;157:505-13.e1-8.

25 Maggio E, Sartore M, Attanasio M, et al. Anti-Vascular endothelial growth factor treatment for diabetic macular edema in a real-world clinical setting. $\mathrm{Am} J$ Ophthalmol 2018;195:209-22.

26 Stewart MW. Treatment of diabetic retinopathy: recent advances and unresolved challenges. World J Diabetes 2016:7:333-41.

27 Cunha-Vaz J, Ashton P, lezzi R, et al. Sustained delivery fluocinolone acetonide vitreous implants: long-term benefit in patients with chronic diabetic macular edema. Ophthalmology 2014;121:1892-903.

28 Jackson TL, Nicod E, Angelis A, et al. Pars plana vitrectomy for vitreomacular traction syndrome: a systematic review and metaanalysis of safety and efficacy. Retina 2013:33:2012-7

29 Presta LG, Chen $\mathrm{H}, \mathrm{O}^{\prime} \mathrm{C}$ onnor SJ, et al. Humanization of an anti-vascular endothelial growth factor monoclonal antibody for the therapy of solid tumors and other disorders. Cancer Res 1997:57:4593-9.

30 Kiss S, Liu Y, Brown J, et al. Clinical utilization of anti-vascular endothelial growthfactor agents and patient monitoring in retinal vein occlusion and diabetic macular edema. Clin Ophthalmol 2014;8:1611-21.

31 Wells JA, Glassman AR, Ayala AR, et al. Aflibercept, bevacizumab, or ranibizumab for diabetic macular edema: two-year results from a comparative effectiveness randomized clinical trial. Ophthalmology 2016;123:1351-9.

32 Heier JS, Bressler NM, Avery RL, et al. Comparison of aflibercept, bevacizumab, and ranibizumab for treatment of diabetic macular edema: extrapolation of data to clinical practice. JAMA Ophthalmol 2016;134:95-9.

33 Ciulla TA, Bracha P, Pollack J, et al. Real-world outcomes of anti-vascular endothelial growth factor therapy in diabetic macular edema in the United States. Ophthalmol Retina 2018:2:1179-87.

34 Dugel PU, Layton A, Varma RB. Diabetic macular edema diagnosis and treatment in the real world: an analysis of Medicare claims data (2008 to 2010). Ophthalmic Surg Lasers Imaging Retina 2016;47:258-67.

35 Hodzic-Hadzibegovic D, Sander BA, Monberg TJ, et al. Diabetic macular oedema treated with intravitreal anti-vascular endothelial growth factor - 2-4 years follow-up of visual acuity and retinal thickness in 566 patients following Danish national guidelines. Acta Ophthalmol 2018;96:267-78.

36 Talks J, Daien V, Finger RP, et al. The use of real-world evidence for evaluating antivascular endothelial growth factor treatment of neovascular age-related macular degeneration. Surv Ophthalmol 2019;64:707-19. 